\title{
Water Channels (Aquaporins) and Their Role for Postnatal Adaptation
}

\author{
MARINA ZELENINA, SERGEY ZELENIN, AND ANITA APERIA \\ Nordic Center of Excellence for Research in Water Imbalance Related Disorders (WIRED), Department of \\ Woman and Child Health, Karolinska Institutet, S-171 76, Stockholm, Sweden
}

\begin{abstract}
ABST
Birth is a transition from an underwater life in the uterus to a
terrestrial life in a milieu where supply of water is limited. Rapid
adaptation to the new environment is crucial for survival and
health of infants. The discovery of a family of molecules-
aquaporin (AQP) water channels-that are responsible for reg-
ulated water transport across cell membranes has made it possi-
ble to identify the molecular mechanisms behind the postnatal
homeostatic adaptation and to better understand water imbal-
ance-related disorders in infancy and childhood. Thirteen mam-
malian AQP isoforms have been identified, most of them having
a unique tissue-specific pattern of expression. Most mammalian
AQPs can be dynamically regulated, which makes them potential
targets for the development of new drugs for diseases associated
\end{abstract}
Water is a prerequisite for life. Water molecules are polar, which allows them to easily form hydrogen bonds with each other and with other molecules. They serve as excellent solvents for a variety of polar substances in the cells. Water provides solvent shells around charged groups of biopolymers. These shells are essential for the biologic activity of proteins (1).

It took hundreds of millions years for ancient vertebrate organisms to adapt from a life with unrestricted water supply to a terrestrial life. This adaptation has involved the development of numerous intricate mechanisms and regulatory systems that allow animals to exist in air environment, where supply of water is more or less limited. Now it takes mammals a few minutes to make the transition from an underwater existence in the uterus to a postnatal terrestrial life. The first immediate task a newborn infant has to deal with is rapid removal of water out of lung air spaces. Maturation of kidney concentrating capacity occurs in humans during the first year of life. The capacity to maintain a proper water balance in the brain and to protect from brain edema may take even longer time.

Received December 15, 2004; accepted January 26, 2005.

Correspondence: Anita Aperia, M.D., Ph.D., Q2:09 Astrid Lindgren Children's Hospital, S-171 76 Stockholm, Sweden; e-mail: Anita.Aperia@kbh.ki.se

Supported by the Nordic Centre of Excellence Programme in Molecular Medicine and by grants from the Swedish Research Council, the Swedish Heart-Lung Foundation, the Märta and Gunnar V. Philipson Foundation, and the Persson Family Foundation. with disturbances in water homeostasis. This review deals with AQP in kidney, lung, and brain. Evidence is presented that AQPs are expressed in a specific age-dependent manner and that the timed expression of AQPs may have a crucial role during the early postnatal period. (Pediatr Res 57: 47R-53R, 2005)

AQP, aquaporin
BPD, bronchopulmonary dysplasia
RDS, respiratory distress syndrome
SIADH, syndrome of inappropriate antidiuretic hormone
secretion

Water comprises about $60 \%$ of our body weight. In newborn full-term infants, total body water fraction is approximately $75 \%$, and in preterm babies approximately $80-85 \%$ of their body mass (2). The ratio between extracellular and intracellular water content changes dramatically in the postnatal period (Fig. 1). Shortly after birth, the body water mass rapidly decreases. This decrease is mainly due to a reduction of extracellular water fraction, which decreases from about $45 \%$ to $30 \%$ of total body mass during the first 3 mo of life.

As late as in 1990, little was known about the molecular mechanism regulating total body water content and the distribution of water between the extracellular and intracellular space. The discovery of integral membrane proteins that function as water channels (3), resulted in a paradigm shift for the understanding of the mechanisms behind transmembrane water transport, water redistribution processes after birth, and many pathologic conditions related to disturbances in water homeostasis.

More than 10 isoforms of water channels, now named AQPs, have been identified in humans to date. Most of them have a common molecular structure, with six transmembrane domains and intracellular $\mathrm{NH}_{2}$ - and $\mathrm{COOH}$-termini. Functionally, $\mathrm{AQPs}$ can be divided into two subfamilies-aquaporins, specialized on transport of water, and aquaglyceroporins, which transport not only water but also small nonpolar molecules like glycerol and urea. 

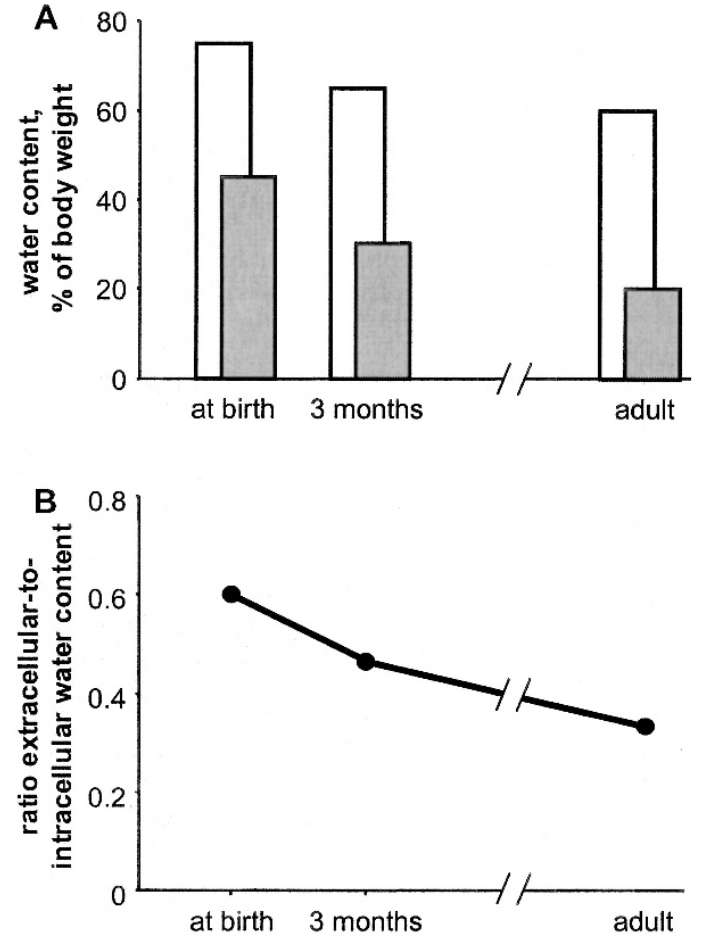

Figure 1. Developmental changes in body water content (estimated from Ref. 2). (A) Total body water content (open bars) and extracellular water content (filled bars). (B) Ratio of water content in extracellular and intracellular compartments.

Water transport via AQPs occurs bidirectionally and is driven by osmotic gradients. The osmotic gradient across the plasma membrane is primarily created by energy-dependent cation transport via $\mathrm{Na}^{+}, \mathrm{K}^{+}$-ATPase. This ion pump, which is present in all mammalian cells, uses the energy from ATP hydrolysis to transport sodium out of the cell and potassium into the cell with the stoichiometry 3:2. In epithelial cells, $\mathrm{Na}^{+}$, $\mathrm{K}^{+}$-ATPase is localized in the basolateral plasma membrane. The sodium gradient created by the pump permits sodium to enter the cell via channels and co-transporters inserted in the apical membrane. This results in a flux of sodium that drives water flow via AQPs in the same direction.

There are, in addition to AQPs, at least three other pathways for water transport in mammalian tissues. These include passive diffusion of water across the plasma membrane lipid bilayer, transport of water via co-transporters such as $\mathrm{Na}^{+}$glutamate or $\mathrm{Na}^{+}$-glucose co-transporter (4), and paracellular water transport via tight junctions.

Water transport via AQPs is much faster than diffusion of water via lipid bilayer of plasma membrane (Fig. 2A). Water transport via most AQPs is also more efficient than via cotransporters (5). Water transport via co-transporters is, however, the main mechanism for water uptake in intestinal epithelial cells, which, in contrast to most other types of epithelial cells, have a very low expression of AQPs (4). Paracellular water transport may be significant in leaky epithelia (6) but is negligible compared with the water channel-mediated transport in tight epithelia (7).

Water movement via $\mathrm{AQP}$ allows a more specific regulation of water distribution than water movement via other pathways.
A
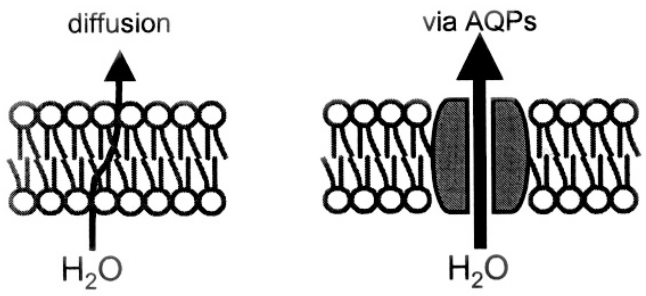

B
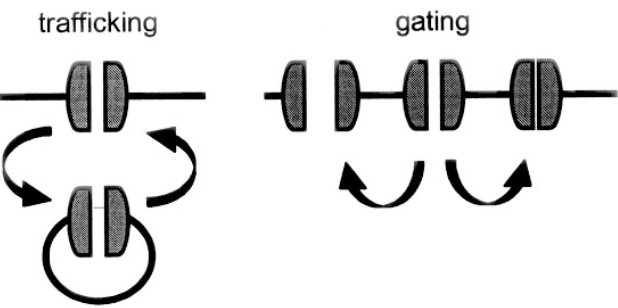

Figure 2. Compared with simple diffusion through the lipid bilayer of the plasma membrane (A, left panel), AQPs water channels ( $A$, right panel) provide much more rapid and energy undemanding transport of water across the plasma membrane. The protein nature of the water pores also offers various possibilities for the regulation of water transport: by trafficking of an AQPS between the plasma membrane and a pool of intracellular vesicles (B, left panel), or by changing permeability of an AQPs residing in the plasma membrane (B, right panel).

Many mammalian AQPs have been shown to be differentially expressed during development and to be regulated by hormones at the level of protein abundance $(8-11)$. The capacity of AQPs to transport water can also be dynamically regulated by hormones and/or extracellular factors such as heavy metals and $\mathrm{pH}(11-24)$. Such dynamic/short-term regulation may occur by changing the opening state of AQP residing in the plasma membrane or by insertion of AQP-containing vesicles into the plasma membrane (Fig. 2B). Information about the mechanisms by which AQPs can be regulated will be a prerequisite for future development of novel therapeutic tools for diseases associated with disturbances in water homeostasis.

Almost all tissues in the human body have a unique set of AQPs that can modulate water balance and cell volume control (Fig. 3). Dysfunction or lack of AQPs has been described in a variety of diseases such as nephrogenic diabetes insipidus, early onset cataract, Sjögren's syndrome, wet lung syndrome, congestive heart failure, SIADH, and brain edema (for reviews on the pathophysiology of AQPs, see Refs. 25,26).

\section{KIDNEY AQPS}

Under normal physiologic conditions, the adult kidney filters approximately $180 \mathrm{~L}$ of plasma fluid a day and excretes only $0.5-2 \mathrm{~L}$ of urine. During severe dehydration, $<0.2 \%$ of the filtrate is excreted; during volume expansion, $>7 \%$ of the filtrate will be excreted. Thus, the variations of transcellular water transport are huge, depending on fluid intake and water losses via skin and lung.

It is now generally recognized that most of the water reabsorption in the nephron occurs transcellularly via AQPs (27). Figure 4 illustrates the expression of AQPs in the nephron. The bulk of water from ultrafiltrate is reabsorbed in proximal part 


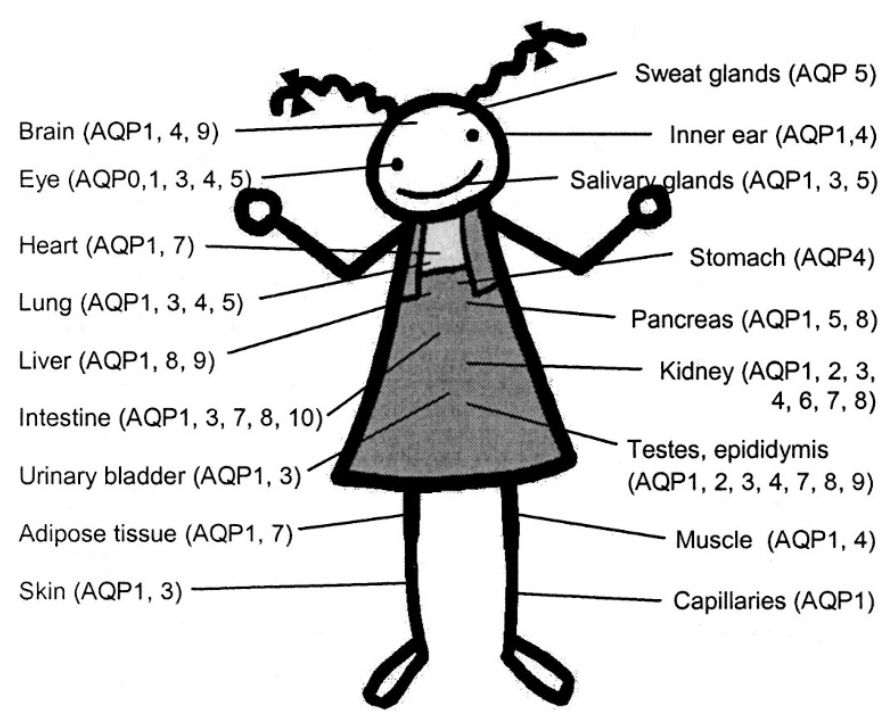

Figure 3. Expression of AQPs isoforms in human tissues.

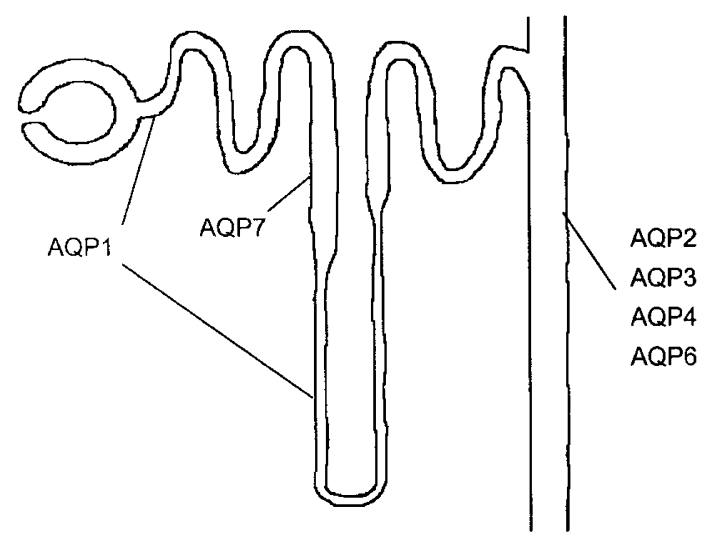

Figure 4. Distribution of AQPs isoforms in the nephron (27). AQP1 is present both in the apical and in the basolateral plasma membrane of proximal tubular cells and in the descending limb of the loop of Henle. AQP2 is localized in the apical plasma membrane and/or in intracellular vesicles in the principal cells of collecting duct. AQP3 and AQP4 are present in the basolateral membrane of the same cells as AQP2. AQP6 is localized in intracellular vesicles in intercalated cells of the collecting duct. AQP7 is present in the apical membranes of proximal straight tubules (S3 segment).

of the nephron via AQP1, which is present both in apical and basolateral plasma membranes of the epithelial cells in proximal tubules and descending limb of loop of Henle. The water reabsorption is driven by osmotic gradients. Ascending limb of Henle's loop and distal convoluted tubule lack AQPs and are water-impermeable. The urine in the distal convoluted tubule is nearly isoosmotic, because sodium is actively reabsorbed in thick ascending limb by $\mathrm{Na}^{+}, \mathrm{K}^{+}$-ATPase. Approximately $15 \%$ of the filtrate is delivered to the collecting duct, where water reabsorption occurs in regulated manner in compliance with the needs of the body. The regulation of the water transport in collecting duct can be attributed to the ability of AQPs to be dynamically regulated (12-16,19-21,24). When the kidney is exposed to antidiuretic hormone, AVP, water is reabsorbed via $\mathrm{AQP} 2$ in the apical plasma membrane and $\mathrm{AQP} 3$ and AQP4 in the basolateral plasma membrane. AVP acts by insertion of AQP2 into the apical plasma membrane of the collecting duct principal cells (see below). Active sodium reabsorption via $\mathrm{Na}^{+}, \mathrm{K}^{+}$-ATPase in water-impermeable thick ascending limb, recirculation of urea, and the countercurrent multiplier mechanism creates a highly hypertonic renal medullary interstitium. This hypertonicity acts as a very strong driving force for the water reabsorption in the collecting duct in the presence of AVP.

$\mathrm{AQP} 2$, the main renal target for AVP, is of major importance for the urinary concentrating capacity. Defects in AQP2 structure cause approximately $10 \%$ of hereditary nephrogenic diabetes insipidus in human population (28). AQP2 abundance is down-regulated in congenital urinary tract obstruction and lithium-induced nephrogenic diabetes insipidus, and is upregulated in congestive heart failure and hepatic cirrhosis (29-33).

AQP2 is located in collecting duct principal cell apical membrane and/or in subapical intracellular vesicles that represent an instantly recruitable reserve for on-demand increasing the water permeability of the collecting duct. These AQP2containing vesicles are recruited to the plasma membrane by AVP and other antidiuretic factors, such as oxytocin (12-15). It is generally agreed that, under basal conditions, there is certain constitutive turnover of AQP2 between the plasma membrane and intracellular vesicles. AVP, acting on V2receptors, increases cAMP production and stimulates protein kinase A dependent phosphorylation of AQP2. Vesicles carrying phosphorylated AQP2 are directed to the apical pole of the cells and fuse with the plasma membrane. The AVP-mediated recruitment of AQP2 to the apical membrane causes a huge increase in the water permeability of the apical plasma membrane. Antidiuretic factors, like prostaglandin $\mathrm{E}_{2}$, can decrease AVP-induced water permeability of the principal cells by shifting the balance between AQP2 exo- and endocytosis in the opposite direction $(19,24)$.

The urinary concentration capacity in humans develops gradually postnatally and reaches full maturation at approximately 18 mo $(34,35)$. The low concentrating capacity in infants provides poor protection against extrarenal water losses and can, in older infants, be associated with increased susceptibility to of hypertonic dehydration. The developmental pattern of AQP2 in kidney has been shown to parallel the development of the concentrating capacity $(8,36-38)$. AQP2 mRNA and AQP2 protein levels increase gradually postnatally and reach adult level by the end of weaning. Both AQP2 expression and the development of the urinary concentrating capacity can be prematurely induced by glucocorticoid hormone treatment (8). It should be noted though that low AQP2 expression is not the only limiting factor in the capacity to concentrate urine $(14,36,38)$ and that maturation of this function also involves development of nephron architecture, the capacity to create a cortico-papillary solute gradient, and development of sensitivity of collecting duct cells to AVP (reviewed in Ref. 39).

The use of indomethacin treatment to suppress prostaglandin production in infants with patent ductus arteriosus often leads to water retention $(40,41)$. In the presence of drugs that suppress endogenous prostaglandin production, AQP2 will remain in the plasma membrane (19). This may explain the water retaining effects of indomethacin treatment in infants. 
Urinary excretion of AQP2 can serve as indicator of AVPAQP2 pathway activity $(42,43)$. We have in ongoing studies found that urinary excretion of AQP2 during first 2-3 postnatal weeks in humans is increased with increasing gestational age at birth. In infants with renal insufficiency, excretion of AQP2 is decreased (44).

AQP1, AQP3, and AQP4 have also been shown to play roles for the concentration of urine. AQP1 is the dominant AQPs isoform in the proximal nephron. It mediates water permeability of both apical and basolateral plasma membranes of tubular epithelium in this nephron segment. In rat proximal tubules, expression of AQP1 mRNA and protein is not detectable in fetus and is induced shortly after birth $(37,45,46)$. Knockout of AQP1 in mice leads to nephrogenic diabetes insipidus (47). In reported cases of AQP1-null humans, a decreased ability to concentrate urine has been demonstrated after dehydration or in response to AVP treatment (48).

AQP4 is located in the basolateral membranes of collecting duct principal cells. AQP4 can be regulated by hormones, but, unlike $\mathrm{AQP} 2$, regulation does not involve a shuttling mechanism $(20,21)$. Activation of protein kinase $\mathrm{C}$ leads to phosphorylation and reduces water permeability of AQP4 residing in the plasma membrane. Interestingly, this effect can be triggered by activation of dopamine receptors. AVP and $\beta$-adrenergic agonist isoproterenol can enhance the water permeability of plasma membrane AQP4, and this effect can be mimicked by adenylyl cyclase activator forskolin.

Rat renal AQP4 mRNA levels increase gradually after birth, indicating a developmental regulation during postnatal life (10). AQP4 protein expression is detected in rat kidney by immunohistochemistry in the very early postnatal period (49).

AQP3 protein is detected early after birth $(37,38)$. AQP3 has so far not been shown to be regulated by hormones, but it has, as described below, a very distinct sensitivity to extracellular $\mathrm{pH}(17,22)$. Acidification of extracellular fluid leads to a decrease of AQP3 water permeability.

\section{LUNG AQPs}

After introduction of surfactant in the early 1990s and the growing use of antenatal steroids since that time, the number of term and preterm infants having severe RDS has declined. However, management of babies suffering from RDS still causes much debate and concern, not least because of the recognized high risk of adverse outcome (50). Acute RDS often develops into a chronic lung disease, BPD. One of the most prominent features of RDS and BPD is lung edema that is believed to be caused by inadequate lung water clearance. Close to term, the human fetal lung secretes approximately 0.5 $\mathrm{L}$ of fluid a day. At birth, the lung epithelium switches from a secretory to absorptive epithelium. This switch involves increased expression of the epithelial sodium channel and of the sodium pump, and also changes in expression of lung AQPs. At birth, most of the lung fluid is expelled mechanically, but some will remain to be absorbed during the first postnatal days. In premature infants this ability of lung to reabsorb water is often impaired, contributing to the still high incidence of RDS and BPD (51).
In the postnatal lung, a thin layer of liquid covers the airways. The depth and composition of airway surface liquid must be strictly controlled to keep the airways free from infection and to maintain an effective gas exchange. Composition of airway surface liquid components affects efficiency of mucus clearance on airway surface, which is important both for an adequate gas exchange and for defense against infections (52). Acidity of airway surface liquid is of particular importance, inasmuch as it can affect mucus clearance by influencing both mucus rheology and ciliary beat frequency (53). Asthma, bronchiectasis, chronic obstructive pulmonary disease, and cystic fibrosis are all associated with an acidified airway surface liquid (54-56).

It is likely that water transport via $\mathrm{AQP}$ is of importance both for lung water clearance at birth and for maintenance of airway surface liquid composition in postnatal life. AQPs are abundantly expressed in the lung. At least four AQP isoforms, $\mathrm{AQP1}, \mathrm{AQP} 3, \mathrm{AQP} 4$, and AQP5, are expressed in the lung tissue (Fig. 5). AQP1 is expressed in capillary endothelium; the other AQPs are localized in the airway epithelial cells. The physiologic role of each AQPs remains to be fully clarified. So far, the function of lung AQPs was mainly studied in rodents (57). Transcapillary osmotic water permeability was greatly reduced by AQP1 deletion, and the airspace-to-capillary water permeability was significantly decreased by additional knockout of AQP4 (58). Because rodent lung epithelium appears to be more leaky than the human, the requirements for a regulated water transport should be more stringent in humans (59). Studies in human AQP1-null individuals have established that AQP1 is a determinant of vascular permeability in the lung (60). Furthermore, the distribution of AQPs in human lung has been reported to be different from that in rodents (61).

The level of AQP1 in the lung endothelium is dramatically increased perinatally and can be further up-regulated by maternal corticosteroid treatment (9).

Expression of AQP4 peaks immediately after birth $(10,62)$, suggesting that this water channel may be critically involved in

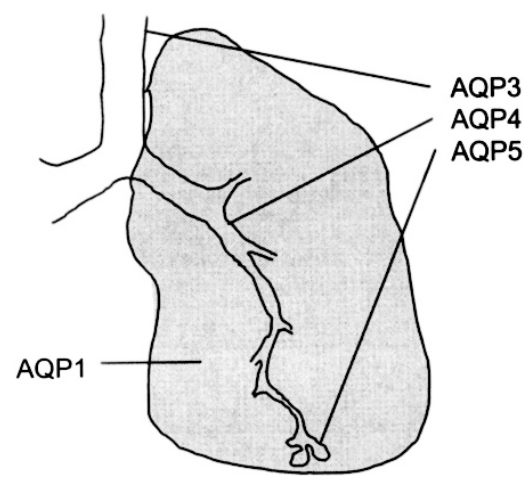

Figure 5. Distribution of AQPs isoforms in the lung (84). AQP1 is expressed in the plasma membranes of endothelial cells of the lung capillaries. AQP3 is localized basolaterally in epithelial cells lining trachea and bronchi. In humans, AQP3-specific signals were also detected in the apical plasma membrane of proximal and terminal bronchioles and in the basolateral membranes of type II pneumocytes (61). AQP4 is expressed in basolateral membranes of tracheal and bronchial epithelium. In humans, AQP4 was also detected in type I pneumocytes in alveoli. AQP5 is localized in apical membranes of type I pneumocytes and in secretory glands in the upper airways. 
lung water clearance. Lung AQP4 mRNA can be prematurely induced in embryonic rats both by glucocorticoids and $\beta$-adrenergic agonists (10). The effect of $\beta$-adrenergic agonists is particularly interesting, since they are well known to improve lung function in preterm infants. We have in an ongoing study using bronchial lavage aspirates from premature babies found that AQP4 abundance in lung can also be up-regulated by maternal corticosteroid treatment in humans. The material was obtained from two groups of newborn preterm babies that only differed with regard to glucocorticoid exposure.

AQP3, localized apically in human alveolar epithelium (61), may be of special clinical interest, since it is $\mathrm{pH}$-regulated $(17,22)$. Extracellular acidification significantly decreases the water permeability of AQP3 expressed in human bronchial epithelial cell line, but does not influence other AQPs expressed in lung epithelium, AQP4 and AQP5 (22). The effect of extracellular $\mathrm{pH}$ on AQP3 is mediated by two histidine residues that are present in the extracellular part of AQP3 molecule. Histidine can bind hydrogen ions at low $\mathrm{pH}$, which may lead to a conformational change in AQP3 molecule resulting in a decreased water permeability of AQP3 water pore. Two other amino acid residues, tyrosine 124 and serine 152 , are also involved in the $\mathrm{pH}$ sensitivity of AQP3. In conditions of airway surface liquid acidification, the AQP3mediated water permeability will be inhibited, which may contribute to the poor lung water clearance in asphyxiated and acidotic babies. AQP3 is also inhibited by heavy metals nickel and copper $(22,23)$. Copper is widely used in water distribution systems, and considerable amounts of copper can be present in the tap water $(63,64)$. Drinking copper-containing water can be especially hazardous for infants because of an imbalance between absorption and excretion of copper in early postnatal period (65).

Alveolar AQP5 may also play a role in regulation of airway surface liquid composition. AQP5 protein level gradually increases after birth (62). It has recently been found that AQP5 can be phosphorylated by protein kinase A, and a sustained exposure to $\beta$-adrenergic agonist increases AQP5 protein expression and membrane localization in the lung (11). The ability of AQP5 to be dynamically regulated makes it an attractive potential target in treatment of lung edema related disorders.

\section{BRAIN AQP}

Three water channels have at the time for this review been reported to be located in the brain: AQP1, AQP4, and AQP9. AQP1 is exclusively expressed in the choroid plexuses (66). AQP4 and AQP9 are both expressed in astrocytes. AQP9 was also detected in a subpopulation of catecholaminergic neurons $(67,68)$. No other water channel has yet been identified in neurons. It has been suggested that water transport in the plasma membrane of neurons might occur via co-transporters such as the $\mathrm{Na}^{+}$-glutamate co-transporter (5). For a recent review on brain AQPs, see Ref. 69.

AQP1 is located in the apical membrane of epithelial cells in the choroid plexus. Studies in knockout mice suggest that it plays an important role in the formation of cerebrospinal fluid
(70). In rat, AQP1 mRNA is expressed early in fetal life (45). Hypothetically, inhibition of AQP1 might be used as a symptomatic therapeutical tool in hydrocephalus. No pharmacological inhibitor of AQP1 exists yet, but studies on AQP1 expressed in Xenopus oocyte expression system and in bile duct epithelial cells have shown that this water channel can be dynamically regulated by hormones such as AVP, atrial natriuretic peptide, and secretin $(16,18)$.

$\mathrm{AQP} 9$, which is also permeable for glycerol and urea, was identified in the brain only a few years ago and its physiologic and pathophysiologic roles remain to be determined. It has been hypothesized that $\mathrm{AQP9}$ may be involved in brain energy metabolism as a neutral solute channel (71).

AQP4 is the most extensively studied brain AQPs. It is expressed in astrocytes and ependymal cells. It is strongly enriched in astrocyte membranes at the interface between brain neuropil and extracerebral spaces. AQP4 is also abundant in osmosensory areas (68).

AQP4 mRNA expression was reported to increase postnatally in extracts from whole rat brain (10). In situ hybridization, semiquantitative immunoblotting, and immunofluorescence microscopy have also revealed very low levels of AQP4 mRNA and protein in the first postnatal week and a significant increase in the second week (72). Little is known, however, about the development of AQP4 expression in different brain regions at the present time.

Under physiologic conditions, AQP4 plays an important protective role by facilitating potassium clearance that occurs after neuronal stimulation $(73,74)$. Reduced efficiency of potassium clearance after neuronal stimulation should be expected to increase the vulnerability to epileptic seizures. Indeed, in transgenic mice, where astrocyte AQP4 is partially lacking and misplaced, the susceptibility to hyperthermiainduced epileptic seizures is enhanced (74). The question of whether certain forms of epilepsy may be associated with abnormalities of brain AQP4 in humans is currently under investigation.

Several conditions such as ischemia, trauma, tumor, infections, hyponatremia, and fulminant hepatic failure are associated with brain edema. Notably, children have a higher susceptibility to brain edema than adults. The presence of AQP4 appears to favor the development of cytotoxic edema (swelling due to increased intracellular fluid). Studies on mice deficient in AQP4 have indicated that in posthypoxic brain edema the presence of AQP4 is harmful (75). In mice where AQP4 was selectively removed from perivascular plasma membrane of astrocytes by dystrophin or $\alpha$-syntrophin deletion, the development of edema after water intoxication and acute hyponatremia was significantly delayed $(76,77)$. The mechanism for this apparently harmful effect remains to be elucidated.

Studies on mice deficient in AQP4 have also indicated that in edema associated with impairment of capillary endothelium the presence of AQP4 may actually have a positive effect on brain water clearance $(78,79)$ by providing an effective path for water removal from the brain parenchyma.

Acute lead intoxication is a condition that causes brain damage preceded by brain edema. Recent studies from our laboratory have shown that lead increases the water permeabil- 
ity of AQP4 expressed in astrocytes (80). Lead, which is readily taken up by astrocytes, appears to enhance AQP4 water permeability via activation of calcium/calmodulin-dependent protein kinases. AQP4 carries several consensus sites for protein phosphorylation. Taking into account the potentially harmful role of AQP4 in many forms of brain edema, it becomes an important topic to elucidate the short- and long-term regulation of this transporter.

It is generally agreed that the capacity of corticosteroids to enhance protein expression is particularly high in the perinatal period. In fetal rat lung, glucocorticoids increase AQP4 mRNA levels (10). So far, there is no report of the effect of corticosteroid on AQPs expression in perinatal or infant brain. If glucocorticoids would stimulate expression of AQP4 in brain, their use in hypoxia and brain edema might, for the reasons given above, be contraindicated. It is therefore important to examine possible effects of glucocorticoids on brain AQP4 in the perinatal period and to consider their possible adverse effects in posthypoxic infants.

AQP4 has two isoforms that differ in the length of $\mathrm{NH}_{2}$ terminus, the longer AQP4.M1 and the shorter AQP4.M23 $(81,82)$. Studies in mice have revealed the presence of at least two mRNA that encode the M23 protein isoform, AQP4.M23 and AQP4.M23X mRNA (83). This opens the possibility that the transcriptional regulation of $\mathrm{AQP} 4$ protein can be tissue specific. In fact, the AQP4.M23X mRNA, which is predominantly expressed in the brain, was found to be developmentally regulated with higher levels in the adult than in the infant mouse.

\section{CONCLUSION AND FUTURE PERSPECTIVES}

AQPs are the main molecular targets for factors regulating water metabolism. Expression of AQPs increases after birth in kidney, lung, and brain. The first water channel was identified less than $15 \mathrm{y}$ ago and the understanding of the physiologic and pathophysiological relevance of the 13 mammalian AQPs that have been identified to date is still incomplete. The significance of renal AQPs for tubular water reabsorption and for urinary concentrating capacity is well established. Emerging evidence suggest important roles for lung and brain AQPs. The physiologic and pathophysiologic role of AQPs for lung water clearance and for excessive lung epithelial fluid secretion in situations such as asthma will need to be clarified. The clinical relevance of the $\mathrm{pH}$ sensitivity of lung AQP3 should be explored. Future studies should also aim at clarifying the physiologic and pathophysiological role of brain AQPs. Of particular importance are the following questions: Will water transport via AQPs enhance astrocyte swelling in hypoxia associated with brain edema and would it therefore be beneficial to down-regulate brain AQPs in these situations? Does AQP dysfunction contribute to certain forms of epilepsy? Can AQPs expressed in the choroids plexus be a target for symptomatic treatment of hydrocephalus? It will be an important task for pediatricians and basic scientists to jointly address these questions.

\section{REFERENCES}

1. Zaccai G 2004 The effect of water on protein dynamics. Philos Trans R Soc Lond B Biol Sci 359:1269-1275, discussion 1275, 1323-1228

2. Friis-Hansen B 1983 Water distribution in the foetus and newborn infant. Acta Paediatr Scand Suppl 305:7-11

3. King LS, Kozono D, Agre P 2004 From structure to disease: the evolving tale of aquaporin biology. Nat Rev Mol Cell Biol 5:687-698

4. Loo DDF, Wright EM, Zeuthen T 2002 Water pumps. J Physiol (Lond) 542:53-60

5. Macaulay N, Hamann S, Zeuthen T 2004 Water transport in the brain: role of cotransporters. Neuroscience 129:1031-1044

6. Whittembury G, Paz-Aliaga A, Biondi A, Carpi-Medina P, Gonzalez E, Linares H 1985 Pathways for volume flow and volume regulation in leaky epithelia. Pflugers Arch 405(suppl 1):S17-S22

7. Flamion B, Spring KR, Abramow M 1995 Adaptation of inner medullary collecting duct to dehydration involves a paracellular pathway. Am J Physiol 268:F53-F63

8. Yasui M, Marples D, Belusa R, Eklof AC, Celsi G, Nielsen S, Aperia A 1996 Development of urinary concentrating capacity: role of aquaporin-2. Am J Physiol 271:F461-F468

9. King LS, Nielsen S, Agre P 1996 Aquaporin-1 water channel protein in lung: ontogeny, steroid-induced expression, and distribution in rat. J Clin Invest 97:21832191

10. Yasui M, Serlachius E, Lofgren M, Belusa R, Nielsen S, Aperia A 1997 Perinatal changes in expression of aquaporin- 4 and other water and ion transporters in rat lung. J Physiol 505:3-11

11. Sidhaye V, Hoffert JD, King LS 2005 cAMP regulation of AQP5: Distinct acute and chronic effects in lung epithelial cells. J Biol Chem 280:3590-3596

12. Deen PM, Verdijk MA, Knoers NV, Wieringa B, Monnens LA, van Os CH, van Oost BA 1994 Requirement of human renal water channel aquaporin-2 for vasopressindependent concentration of urine. Science 264:92-95

13. Nielsen S, Chou CL, Marples D, Christensen EI, Kishore BK, Knepper MA 1995 Vasopressin increases water permeability of kidney collecting duct by inducing translocation of aquaporin-CD water channels to plasma membrane. Proc Natl Acad Sci U S A 92:1013-1017

14. Sabolic I, Katsura T, Verbavatz JM, Brown D 1995 The AQP2 water channel: effect of vasopressin treatment, microtubule disruption, and distribution in neonatal rats. J Membr Biol 143:165-175

15. Chou CL, DiGiovanni SR, Mejia R, Nielsen S, Knepper MA 1995 Oxytocin as an antidiuretic hormone. I. Concentration dependence of action. Am J Physiol 269:F70-77

16. Patil RV, Han Z, Wax MB 1997 Regulation of water channel activity of aquaporin 1 by arginine vasopressin and atrial natriuretic peptide. Biochem Biophys Res Commun 238:392-396

17. Zeuthen T, Klaerke DA 1999 Transport of water and glycerol in aquaporin 3 is gated by $\mathrm{H}(+)$. J Biol Chem 274:21631-21636

18. Marinelli RA, Tietz PS, Pham LD, Rueckert L, Agre P, LaRusso NF 1999 Secretin induces the apical insertion of aquaporin-1 water channels in rat cholangiocytes. Am J Physiol 276:G280-G286

19. Zelenina M, Christensen BM, Palmer J, Nairn AC, Nielsen S, Aperia A 2000 Prostaglandin E(2) interaction with AVP: effects on AQP2 phosphorylation and distribution. Am J Physiol Renal Physiol 278:F388-F394

20. Zelenina M, Zelenin S, Bondar A, Brismar H, Aperia A 2001 Aquaporin 4 is bidirectionally regulated by vasopressin and dopamine. J Am Soc Nephrol 12:26A

21. Zelenina M, Zelenin S, Bondar AA, Brismar H, Aperia A 2002 Water permeability of aquaporin-4 is decreased by protein kinase $\mathrm{C}$ and dopamine. Am J Physiol Renal Physiol 283:F309-F318

22. Zelenina M, Bondar AA, Zelenin S, Aperia A 2003 Nickel and extracellular acidification inhibit the water permeability of human aquaporin-3 in lung epithelial cells. J Biol Chem 278:30037-30043

23. Zelenina M, Tritto S, Bondar AA, Zelenin S, Aperia A 2004 Copper inhibits the water and glycerol permeability of aquaporin-3. J Biol Chem 279:51939-51943

24. Nejsum LN, Zelenina M, Aperia A, Frokiaer J, Nielsen S 2004 Bidirectional regulation of AQP2 trafficking and recycling: involvement of AQP2-S256 phosphorylation. Am J Physiol Renal Physiol Dec 29 [Epub ahead of print]

25. Agre P, King LS, Yasui M, Guggino WB, Ottersen OP, Fujiyoshi Y, Engel A, Nielsen S 2002 Aquaporin water channels-from atomic structure to clinical medicine. J Physiol 542:3-16

26. Agre P, Kozono D 2003 Aquaporin water channels: molecular mechanisms for human diseases. FEBS Lett 555:72-78

27. Nielsen S, Frokiaer J, Marples D, Kwon TH, Agre P, Knepper MA 2002 Aquaporins in the kidney: from molecules to medicine. Physiol Rev 82:205-244

28. van Os CH, Deen PM 1998 Aquaporin-2 water channel mutations causing nephrogenic diabetes insipidus. Proc Assoc Am Physicians 110:395-400

29. Kwon TH, Laursen UH, Marples D, Maunsbach AB, Knepper MA, Frokiaer J, Nielsen S 2000 Altered expression of renal AQPs and $\mathrm{Na}(+)$ transporters in rats with lithium-induced NDI. Am J Physiol Renal Physiol 279:F552-F564

30. Xu DL, Martin PY, Ohara M, St John J, Pattison T, Meng X, Morris K, Kim JK, Schrier RW 1997 Upregulation of aquaporin-2 water channel expression in chronic heart failure rat. J Clin Invest 99:1500-1505

31. Nielsen S, Terris J, Andersen D, Ecelbarger C, Frokiaer J, Jonassen T, Marples D, Knepper MA, Petersen JS 1997 Congestive heart failure in rats is associated with increased expression and targeting of aquaporin-2 water channel in collecting duct. Proc Natl Acad Sci U S A 94:5450-5455

32. Asahina Y, Izumi N, Enomoto N, Sasaki S, Fushimi K, Marumo F, Sato C 1995 Increased gene expression of water channel in cirrhotic rat kidneys. Hepatology $21: 169-173$ 
33. Shi Y, Li C, Thomsen K, Jorgensen TM, Knepper MA, Nielsen S, Djurhuus JC, Frokiaer J 2004 Neonatal ureteral obstruction alters expression of renal sodium transporters and aquaporin water channels. Kidney Int 66:203-215

34. Polácek E, Vocel J, Neugebauerová L, Sebková M, Véchetová E 1965 The osmotic concentrating ability in healthy infants and children. Arch Dis Child 40:291-295

35. Hansen JD, Smith CA 1953 Effects of withholding fluid in the immediate postnatal period. Pediatrics 12:99-113

36. Bonilla-Felix M, Jiang W 1997 Aquaporin-2 in the immature rat: expression, regulation, and trafficking. J Am Soc Nephrol 8:1502-1509

37. Yamamoto T, Sasaki S, Fushimi K, Ishibashi K, Yaoita E, Kawasaki K, Fujinaka H, Marumo F, Kihara I 1997 Expression of AQPs family in rat kidneys during development and maturation. Am J Physiol 272:F198-F204

38. Baum MA, Ruddy MK, Hosselet CA, Harris HW 1998 The perinatal expression of aquaporin-2 and aquaporin-3 in developing kidney. Pediatr Res 43:783-790

39. Aperia A, Celsi G 1992 Ontogenic processes in nephron epithelia. Structure, en zymes, and function. In: Seldin DW, Giebisch G (eds) The Kidney: Physiology and Pathophysiology. Raven Press, New York, pp 803-828

40. Cifuentes RF, Olley PM, Balfe JW, Radde IC, Soldin SJ 1979 Indomethacin and rena function in premature infants with persistent patent ductus arteriosus. J Pediatr 95:583-587

41. John EG, Vasan U, Hastreiter AR, Bhat R, Evans MA 1984 Intravenous indomethacin and changes of renal function in premature infants with patent ductus arteriosus. Pediatr Pharmacol (New York) 4:11-19

42. Rai T, Sekine K, Kanno K, Hata K, Miura M, Mizushima A, Marumo F, Sasaki S 1997 Urinary excretion of aquaporin-2 water channel protein in human and rat. J Am Soc Nephrol 8:1357-1362

43. Wen H, Frokiaer J, Kwon TH, Nielsen S 1999 Urinary excretion of aquaporin-2 in rat is mediated by a vasopressin-dependent apical pathway. J Am Soc Nephrol 10:14161429

44. Casper C, Zelenina M, Li Y, Glorieux I, Bloom MC, Decramer S, Aperia A 2004 Urinary excretion of aquaporin 2 in term and preterm infants. Proceedings of the 45th Annual Meeting of the European Society for Paediatric Research, Stockholm, Sweden, p 304

45. Bondy C, Chin E, Smith BL, Preston GM, Agre P 1993 Developmental gene expression and tissue distribution of the CHIP28 water-channel protein. Proc Natl Acad Sci U S A 90:4500-4504

46. Smith BL, Baumgarten R, Nielsen S, Raben D, Zeidel ML, Agre P 1993 Concurrent expression of erythroid and renal aquaporin CHIP and appearance of water channel activity in perinatal rats. J Clin Invest 92:2035-2041

47. Ma T, Yang B, Gillespie A, Carlson EJ, Epstein CJ, Verkman AS 1998 Severely impaired urinary concentrating ability in transgenic mice lacking aquaporin-1 water channels. J Biol Chem 273:4296-4299

48. King LS, Choi M, Fernandez PC, Cartron JP, Agre P 2001 Defective urinaryconcentrating ability due to a complete deficiency of aquaporin-1. N Engl J Med 345:175-179

49. Kim YH, Earm JH, Ma T, Verkman AS, Knepper MA, Madsen KM, Kim J 2001 Aquaporin-4 expression in adult and developing mouse and rat kidney. J Am Soc Nephrol 12:1795-1804

50. Field D 2002 Alternative strategies for the management of respiratory failure in the newborn-clinical realities. Semin Neonatol 7:429-436

51. Modi N 2003 Clinical implications of postnatal alterations in body water distribution. Semin Neonatol 8:301-306

52. Boucher RC 2003 Regulation of airway surface liquid volume by human airway epithelia. Pflugers Arch 445:495-498

53. Inglis SK, Wilson SM, Olver RE 2003 Secretion of acid and base equivalents by intact distal airways. Am J Physiol Lung Cell Mol Physiol 284:L855-L862

54. Hunt JF, Fang K, Malik R, Snyder A, Malhotra N, Platts-Mills TA, Gaston B 2000 Endogenous airway acidification. Implications for asthma pathophysiology. Am J Respir Crit Care Med 161:694-699

55. Kostikas K, Papatheodorou G, Ganas K, Psathakis K, Panagou P, Loukides S 2002 $\mathrm{pH}$ in expired breath condensate of patients with inflammatory airway diseases. Am J Respir Crit Care Med 165:1364-1370

56. Coakley RD, Grubb BR, Paradiso AM, Gatzy JT, Johnson LG, Kreda SM, O'Neal WK, Boucher RC 2003 Abnormal surface liquid pH regulation by cultured cystic fibrosis bronchial epithelium. Proc Natl Acad Sci U S A 100:16083-16088

57. Borok Z, Verkman AS 2002 Lung edema clearance: 20 years of progress: invited review: role of aquaporin water channels in fluid transport in lung and airways. J App Physiol 93:2199-2206

58. Song Y, Ma T, Matthay MA, Verkman AS 2000 Role of aquaporin-4 in airspace-tocapillary water permeability in intact mouse lung measured by a novel gravimetric method. J Gen Physiol 115:17-27

59. King LS, Agre P 2001 Man is not a rodent: aquaporins in the airways. Am J Respir Cell Mol Biol 24:221-223
60. King LS, Nielsen S, Agre P, Brown RH 2002 Decreased pulmonary vascular permeability in aquaporin-1-null humans. Proc Natl Acad Sci U S A 99:1059-1063

61. Kreda SM, Gynn MC, Fenstermacher DA, Boucher RC, Gabriel SE 2001 Expression and localization of epithelial aquaporins in the adult human lung. Am J Respir Cell Mol Biol 24:224-234

62. King LS, Nielsen S, Agre P 1997 Aquaporins in complex tissues. I. Developmental patterns in respiratory and glandular tissues of rat. Am J Physiol Cell Physiol 273:C1541-C1548

63. Alam IA, Sadiq M 1989 Metal contamination of drinking water from corrosion of distribution pipes. Environ Pollut 57:167-178

64. Hoveyda N, Yates B, Bond CR, Hunter PR 2003 A cluster of cases of abdominal pain possibly associated with high copper levels in a private water supply. J Environ Health 66:29-32

65. Bremner I 1998 Manifestations of copper excess. Am J Clin Nutr 67:1069S-1073S

66. Nielsen S, Smith BL, Christensen EI, Agre P 1993 Distribution of the aquaporin CHIP in secretory and resorptive epithelia and capillary endothelia. Proc Natl Acad Sci U S A 90:7275-7279

67. Badaut J, Petit JM, Brunet JF, Magistretti PJ, Charriaut-Marlangue C, Regli L 2004 Distribution of aquaporin 9 in the adult rat brain: preferential expression in catecholaminergic neurons and in glial cells. Neuroscience 128:27-38

68. Nielsen S, Nagelhus EA, Amiry-Moghaddam M, Bourque C, Agre P, Ottersen OP 1997 Specialized membrane domains for water transport in glial cells: high-resolution immunogold cytochemistry of aquaporin-4 in rat brain. J Neurosci 17:171-180

69. Amiry-Moghaddam M, Ottersen OP 2003 The molecular basis of water transport in the brain. Nat Rev Neurosci 4:991-1001

70. Oshio K, Song Y, Verkman AS, Manley GT 2003 Aquaporin-1 deletion reduces osmotic water permeability and cerebrospinal fluid production. Acta Neurochir Suppl 86:525-528

71. Badaut J, Regli L 2004 Distribution and possible roles of aquaporin 9 in the brain Neuroscience 129:971-981

72. Wen H, Nagelhus EA, Amiry-Moghaddam M, Agre P, Ottersen OP, Nielsen S 1999 Ontogeny of water transport in rat brain: postnatal expression of the aquaporin-4 water channel. Eur J Neurosci 11:935-945

73. Nagelhus EA, Horio Y, Inanobe A, Fujita A, Haug FM, Nielsen S, Kurachi Y, Ottersen OP 1999 Immunogold evidence suggests that coupling of $\mathrm{K}+$ siphoning and water transport in rat retinal Muller cells is mediated by a coenrichment of Kir4.1 and AQP4 in specific membrane domains. Glia 26:47-54

74. Amiry-Moghaddam M, Williamson A, Palomba M, Eid T, de Lanerolle NC, Nagelhus EA, Adams ME, Froehner SC, Agre P, Ottersen OP 2003 Delayed K+ clearance associated with aquaporin- 4 mislocalization: phenotypic defects in brains of alpha-syntrophin-null mice. Proc Natl Acad Sci U S A 100:13615-13620

75. Manley GT, Fujimura M, Ma T, Noshita N, Filiz F, Bollen AW, Chan P, Verkman AS 2000 Aquaporin-4 deletion in mice reduces brain edema after acute water intoxication and ischemic stroke. Nat Med 6:159-163

76. Vajda Z, Pedersen M, Fuchtbauer EM, Wertz K, Stodkilde-Jorgensen H, Sulyok E, Doczi T, Neely JD, Agre P, Frokiaer J, Nielsen S 2002 Delayed onset of brain edema and mislocalization of aquaporin-4 in dystrophin-null transgenic mice. Proc Nat Acad Sci U S A 99:13131-13136

77. Amiry-Moghaddam M, Xue R, Haug FM, Neely JD, Bhardwaj A, Agre P, Adams ME, Froehner SC, Mori S, Ottersen OP 2004 Alpha-syntrophin deletion removes the perivascular but not endothelial pool of aquaporin-4 at the blood-brain barrier and delays the development of brain edema in an experimental model of acute hyponatremia. FASEB J 18:542-544

78. Manley GT, Binder DK, Papadopoulos MC, Verkman AS 2004 New insights into water transport and edema in the central nervous system from phenotype analysis of aquaporin-4 null mice. Neuroscience 129:981-989

79. Papadopoulos MC, Saadoun S, Binder DK, Manley GT, Krishna S, Verkman AS 2004 Molecular mechanisms of brain tumor edema. Neuroscience 129:1011-1020

80. Gunnarson E, Baturina G, Zelenina M, Brismar H 2003 Water permeability in astrocytes and the effect of lead intoxication. Proceedings of the 33rd Annual Meeting of Society for Neuroscience, New Orleans, LA

81. Jung JS, Bhat RV, Preston GM, Guggino WB, Baraban JM, Agre P 1994 Molecula characterization of an aquaporin cDNA from brain: candidate osmoreceptor and regulator of water balance. Proc Natl Acad Sci U S A 91:13052-13056

82. Lu M, Lee MD, Smith BL, Jung JS, Agre P, Verdijk MA, Merkx G, Rijss JP, Deen PM 1996 The human AQP4 gene: definition of the locus encoding two water channel polypeptides in brain. Proc Natl Acad Sci U S A 93:10908-10912

83. Zelenin S, Gunnarson E, Alikina T, Bondar A, Aperia A 2000 Identification of a new form of AQP4 mRNA that is developmentally expressed in mouse brain. Pediatr Res 48:335-339

84. Nielsen S, King LS, Christensen BM, Agre P 1997 Aquaporins in complex tissues. II. Subcellular distribution in respiratory and glandular tissues of rat. Am J Physiol 273:C1549-C1561 